\title{
Mechanical and Metabolic Characterization of Ischemic Contracture in the Neonatal Pig Heart
}

\author{
ROBERT J. ASCUITTO, NANCY T. ROSS-ASCUITTO, DONALD W. KYDON, ${ }^{1}$ \\ ALICE E. WADDELL, AND KATHLEEN H. MCDONOUGH \\ Department of Pediatrics, Section of Cardiology, Tulane University School of Medicine, New Orleans, \\ Louisiana 70112 [R.J.A., N.T.R.-A., D.W.K., A.E.W.] and Department of Physiology, Louisiana State \\ University School of Medicine, New Orleans, Louisana 70112 [K.H.M.]
}

\begin{abstract}
Isolated, paced, isovolumetrically beating piglet hearts $(n=$ 37) underwent retrograde aortic perfusion with a crystalloid solution during three periods: 1) baseline (coronary perfusion pressure $60 \mathrm{~mm} \mathrm{Hg}$ ), 2) ischemia (coronary flow $10 \%$ of baseline for $\approx 80 \mathrm{~min}$ ), and 3 ) reperfusion (perfusion pressure returned to baseline). In one group of hearts, glycolysis (using ${ }^{3} \mathrm{H}_{2} \mathrm{O}$ formation from $\left[{ }^{3} \mathrm{H}\right]$ glucose) was assessed. During baseline, peak systolic pressure (PSP) was $101.1 \pm 5.0 \mathrm{~mm} \mathrm{Hg}$, end diastolic pressure (EDP) $4.4 \pm 0.5 \mathrm{~mm} \mathrm{Hg}$, glycolysis $970.5 \pm 65.3$ $\mathrm{nmol} / \mathrm{min} / \mathrm{g}_{\mathrm{wce}}$, and myocardial glycogen $234.8 \pm 12.0 \mu \mathrm{mol} /$ $\mathrm{g}_{\text {dry }}$. During ischemia, PSP decreased to $23.3 \pm 2.7 \mathrm{~mm} \mathrm{Hg}$, EDP increased to $12.3 \pm 0.7 \mathrm{~mm} \mathrm{Hg}$, myocardial glycogen decreased to $181.5 \pm 30.3 \mu \mathrm{mol} / \mathrm{g}_{\mathrm{dry}}$, and lactate $(\approx 154 \mu \mathrm{mol} /$ $\left.\mathrm{g}_{\text {wet }}\right)$ and glycerol $\left(\approx 930 \mathrm{nmol} / \mathrm{g}_{\mathrm{wet}}\right)$ were released. Myocardial contracture correlated with a decrease in lactate release. Glycolysis decreased to $\approx 400 \mathrm{nmol} / \mathrm{min} / \mathrm{g}_{\text {wet }}$ and remained stable, accounting for $\approx 50 \%$ of the lactate produced. During reperfusion, PSP recovered to $79.8 \pm 3.5 \mathrm{~mm} \mathrm{Hg}$, EDP $6.6 \pm 1.7$ $\mathrm{mm} \mathrm{Hg}$, and glycolysis $1103.9 \pm 81 \mathrm{nmol} / \mathrm{min} / \mathrm{g}_{\text {wer }}$. In a second group of hearts, with similar mechanical responses, glucose oxidation (using ${ }^{14} \mathrm{CO}_{2}$ formation from $\left[{ }^{14} \mathrm{C}\right]$ glucose) was evaluated. During baseline, glucose oxidation was $165.4 \pm 15.9$ $\mathrm{nmol} / \mathrm{min} / \mathrm{g}_{\mathrm{wct}}$ and correlated closely $(r=0.957)$ with mechanical activity. With ischemia, glucose oxidation decreased to $\approx 17$
\end{abstract}

ABSTRACT
Myocardial contracture represents a state of decreased diastolic compliance of the ventricle secondary to a depletion of high energy stores in the region of the contractile apparatus (1). With ischemia, contracture occurs as a consequence of myocardial underperfusion, which results in inadequate substrate delivery and impaired ATP production. Insufficient ATP leads to a progressive increase in the number of myocin-actin complexes that are unable to dissociate and to derangements in resting cytosolic calcium levels (2).

Received July 8, 1994; accepted March 18, 1995

Corrrespondence: Robert J. Ascuitto, M.D., Ph.D., Department of Pediatrics, Section of Cardiology, Tulane Ĺniversity School of Medicine, 1430 Tulane Ave., New Orleans, LA 70112

Funded by Grant HL-45603 awarded by the National Institutes of Health.

${ }^{1}$ On leave from the Department of Physics, University of Winnipeg, Manitoba, Canada. $\mathrm{nmol} / \mathrm{min} / \mathrm{g}_{\mathrm{wcl}}$, yet accounted for $\approx 42 \%$ of the ATP produced Upon reperfusion, glucose oxidation returned to baseline values, but now correlated poorly $(r=0.574)$ with mechanical activity. We conclude that for neonatal hearts undergoing severe low-flow ischemia: 1) myocardial contracture is associated with a decline in lactate release, implying impaired lactate production and/or clearance; 2) glycolysis may not fully account for the lactate released, suggesting nonglycolytic sources for energy production; 3) glycerol release is stimulated, indicating hydrolysis of triacylglycerols; 4) glucose oxidation provides an important source of ATP; and 5) glycolysis and glucose oxidation return to baseline values upon reperfusion, despite depressed contractile function, indicating dissociation between mechanical and metabolic recovery. (Pediatr Res 38: 228-236, 1995)

\author{
Abbreviations \\ PSP, peak systolic pressure \\ EDP, end diastolic pressure \\ $(+) \mathbf{d P} / \mathbf{d t}_{\max }$, maximum rate of rise of pressure with respect to \\ time \\ $\mathbf{P a O}_{2}$, partial pressure oxygen (arterial) \\ $\mathrm{Pvo}_{2}$, partial pressure oxygen (venous) \\ $\mathbf{M V O}_{2}$, myocardial oxygen consumption
}

Previous investigations of myocardial contracture in neonates have focused on immature hearts in an arrested state with zero coronary flow $(3,4)$. Little is known about myocardial contracture in the setting of low-flow ischemia, where hearts are beating, and there is washout of metabolites. Additionally, the modalities of encrgy production and utilization associated with contracture are poorly understood, yet these processes ultimately determine myocardial viability. An understanding of these processes in neonatal hearts has significant clinical ramifications, because contracture is thought to represent a precursor to an irreversible myocardial injury (5).

The objectives of the present investigation were to study myocardial contracture in isolated, isovolumetrically beating, neonatal pig hearts subjected to normothermic, low-flow isch- 
emia. Mechanical and metabolic responses were evaluated in hearts perfused with a solution that favored glucose utilization, because glucose has been recognized as an important substrate for the prevention of ischemic contracture in mature hearts (6) and has been used clinically as a resuscitative agent to promote recovery of myocardial contractile function after ischemic injury (7). We speculated that contracture might be associated with an alteration in substrate metabolism, through lactate release, because lactate is an end product of anaerobiasis. Functional recovery after ischemic contracture was also investigated in reperfused hearts.

\section{METHODS}

Preparation of perfusate. The perfusate $\left(37^{\circ} \mathrm{C}\right)$ consisted of insulin $(100 \mu \mathrm{U} / \mathrm{mL})$; the following salts in $\mathrm{mM}: \mathrm{NaCl}, 118$; $\mathrm{KCl}, 4.7 ; \mathrm{MgSO}_{4}, 2.4 ; \mathrm{KH}_{2} \mathrm{PO}_{4}, 1.2 ; \mathrm{NaHCO}_{3}, 25 ; \mathrm{CaCl}_{2}, 2.4$; NaEDTA, $0.1 \mathrm{mM}$; glucose $5.5 \mathrm{mM}$; and 2\% BSA (Fraction V, RIA grade, $>98 \%$ purity, U.S. Biochemical Corp., Cleveland, $\mathrm{OH})$. Supplementary fatty acids were not included in the perfusate. The $\mathrm{pH}$ of the solution was adjusted to $7.4-7.45$ by titration with $1 \mathrm{~N} \mathrm{NaOH}$.

Excision of hearts. Pigs, less than 3 d of age, were used for these studies, because they compare favorably in size with those of humans of similar maturity. Piglets were anesthetized with sodium pentobarbital ( $25 \mathrm{mg} / \mathrm{kg}$ i.p.), anticoagulated with sodium heparin (1000 U/kg i.v.), and mechanically ventilated via a tracheostomy. A midline sternotomy was then performed to expose the heart and great vessels.

A catheter was advanced into the aortic root via the right carotid artery, and the remaining aortic arch vessels were ligated. After ligation of the cavae, incisions were made in the main pulmonary artery and pulmonary veins to decompress the heart. The transverse aortic arch was then cross-clamped. Topical cooling of the heart with ice-cold saline was begun, while simultaneously $4^{\circ} \mathrm{C}$ cardioplegic solution $(\approx 30 \mathrm{~mL} / \mathrm{kg}$ body weight) was administered over $\approx 2 \mathrm{~min}$, via the aortic root catheter. Cardioplegic solution was prepared from a stock solution of $5 \%$ dextrose and $0.45 \% \mathrm{NaCl}$, to which $\mathrm{KCl}$ and $\mathrm{NaHCO}_{3}$ were added to yield final concentrations of $16 \mathrm{mEq} / \mathrm{L}$ each (8). The $\mathrm{pH}$ of the cardioplegic solutions at $4^{\circ} \mathrm{C}$ was $\approx 7.8$. After cardioplegia, the hearts were excised and immediately placed in ice-cold Krebs-Henseleit solution.

Perfusion of isolated hearts. The aorta was cannulated, and each heart underwent retrograde aortic perfusion using the modified Langendorff system described previously (9-11). The time that elapsed between excision of hearts and initiation of retrograde aortic perfusion was less than $5 \mathrm{~min}$. The pulmonary artery was cannulated, and the pulmonary veins were ligated. The coronary perfusion pressure was continuously monitored with a pressure transducer attached to a side port just above the heart. In this preparation, coronary venous return eggressed from the pulmonary artery cannula. Hearts were paced at $180 \mathrm{bpm}$ via the right ventricle, so that ventricular contractions would be maintained at a constant rate when studying low-flow ischemia, which could have affected atrioventricular conduction. The arterial perfusate was preoxygenated with a pediatric oxygenator (Bently), using a mixture of
95\% $\mathrm{O}_{2}-5 \% \mathrm{CO}_{2}$, and then passed through the Langendorff column. This procedure yielded a final arterial $\mathrm{Po}_{2}$ of $\approx 73 \mathrm{kPa}$ $(\approx 550 \mathrm{~mm} \mathrm{Hg}$ ). A "nonrecirculating system" was used to ensure delivery of steady state concentrations of substrates to the heart, and to avoid effects from unrecognized metabolites.

Coronary flow and mechanical function. Coronary flow was measured by timed collections of the pulmonary artery (coronary venous) effluent. Left ventricular isovolumic PSP, the maximum rate of rise of systolic pressure with respect to time $\left(+\mathrm{dP} / \mathrm{dt}_{\max }\right)$ and EDP were recorded continuously via a fluid-filled balloon catheter in the left ventricular chamber. The EDP was adjusted by changing the volume of fluid in the balloon. Any fluid within the ventricular chamber, e.g. from the Thebesian circulation, was vented through an apical stab wound. This maneuver reduces the possibility that a fluid collection around the balloon could alter EDP (9-11).

Metabolic function. Lactate release was studied as a means of characterizing oxygen insufficiency. Lactate concentrations were measured on arterial and venous perfusate samples (12). Rates of lactate release $\left(\mu \mathrm{mol} / \mathrm{min} / \mathrm{g}_{\mathrm{wet}}\right)$ were calculated from: the arteriovenous lactate concentration difference and coronary flow. Because the arterial perfusate contained no lactate, any lactate detected in the coronary venous effluent was lactate that was released by the heart.

Glycolysis from exogenously supplied glucose was estimated by measuring tritiated water $\left({ }^{3} \mathrm{H}_{2} \mathrm{O}\right)$ production (released at the phosphoglucoseisomerase step) from $\mathrm{D}-2\left[{ }^{3} \mathrm{H}(\mathrm{N})\right]-$ glucose $(100 \mu \mathrm{Ci} / \mathrm{L})$, according to the techniques originally described by Neely et al. (13), and Rovetto et al. (14). The ${ }^{3} \mathrm{H}_{2} \mathrm{O}$ was separated from $\left[{ }^{3} \mathrm{H}\right]$ glucose using columns containing Dowex 1X4 anion exchange resin (200-400 mesh) suspended in $0.2 \mathrm{M}$ potassium tetraborate. A $0.5-\mathrm{mL}$ volume of perfusate was added to the column and eluted into scintillation vials with $1.5 \mathrm{~mL}$ of deionized $\mathrm{H}_{2} \mathrm{O}$. The column was then rinsed with an additional $2.0 \mathrm{~mL}$ of $\mathrm{H}_{2} \mathrm{O}$, which was collected in a separate scintillation vial. After addition of Eco-Lite scintillant (ICN Biochemicals, Costa Mesa, CA), the vials were counted in a scintillation counter, with the window set at 0-300 nm. The counts (minus background) from both vials were added to give the total counts for the sample. Rates of glycolysis ( $\mathrm{nmol} / \mathrm{min} / \mathrm{g}_{\mathrm{wet}}$ ) were calculated from the measured specific activity of the $\left[{ }^{3} \mathrm{H}\right]$ glucose in the perfusate; the arteriovenous ${ }^{3} \mathrm{H}_{2} \mathrm{O}$ production difference and the coronary flow.

Myocardial glycogen content was measured in hearts that were freeze-clamped using aluminum blocks $(12 \times 8.5 \times 2.5$ $\mathrm{cm}$ ) precooled with liquid nitrogen. Glycogen was extracted by homogenizing ventricular tissue with $1 \mathrm{~N}$ perchloric acid, followed by neutralization with $5 \mathrm{~N}$ K.OH. The extracts were then incubated with amyloglucosidase, and the liberated glucose was measured fluorometrically (15).

Oxidation of exogenously supplied glucose was estimated by measuring ${ }^{14} \mathrm{CO}_{2}$ production (liberated at pyruvate dehydrogenase and the Krebs cycle) from $\left[\mathrm{U}-{ }^{14} \mathrm{C}\right]$ glucose $(100$ $\mu \mathrm{Ci} / \mathrm{L}$ ), using the method we have described previously (9). A 3-mL sample of perfusate was obtained anaerobically, and injected into a stoppered Erlenmeyer flask containing $1 \mathrm{~N} \mathrm{HCl}$ (to release $\mathrm{CO}_{2}$ ) and a center well with Hyamine hydroxide (to collect $\left.\mathrm{CO}_{2}\right)$. After $12 \mathrm{~h}$ of incubation $\left(45^{\circ} \mathrm{C}\right)$, the wells were 
placed in Ready Organic scintillant, and the ${ }^{14} \mathrm{CO}_{2}$ determined by counting with the window set at 397-655 nm. Rates of glucose oxidation $\left(\mathrm{nmol} / \mathrm{min} / \mathrm{g}_{\mathrm{wet}}\right)$ were calculated from: the measured specific activity of $\left[{ }^{14} \mathrm{C}\right]$ glucose in the perfusate; the arteriovenous ${ }^{14} \mathrm{CO}_{2}$ production difference and the coronary flow. The contribution of glucose oxidation to oxygen consumption was calculated by assuming $6 \mathrm{~mol}$ of oxygen $/ \mathrm{mol}$ glucose.

Myocardial oxygen consumption $\left(\mathrm{MVO}_{2}, \mu \mathrm{mol} \mathrm{O}_{2} / \mathrm{min} /\right.$ $\left.\mathrm{g}_{\text {wet }}\right)$ was calculated as $\left(\mathrm{PaO}_{2}-\mathrm{PvO}_{2}\right) \times \mathrm{C} \times$ coronary flow, where $\mathrm{PaO}_{2}$ and $\mathrm{PvO}_{2}$ refer to the arterial and venous partial pressures of oxygen $(\mathrm{kPa})$, respectively, and where $\mathrm{C}=(0.23$ $\left.\mu \mathrm{L} \mathrm{O} \mathrm{O}_{2} / \mathrm{mL} / \mathrm{kP}_{\mathrm{a}}\right) /\left(22.4 \mu \mathrm{L} \mathrm{O} \mathrm{O}_{2} / \mu \mathrm{mol}\right)$. Samples for $\mathrm{Po}_{2}$ were obtained simultaneously from the aortic perfusion line and pulmonary artery cannula. Oxygen partial pressures were measured directly with a blood gas analyzer (Corning, Medfield, MA).

Average rates of ATP production from glycolysis were calculated by assuming $2 \mathrm{~mol} \mathrm{ATP} / \mathrm{mol}$ exogenous glucose. The ATP production from subsequent oxidative phosphorylation of glucose was calculated by assuming $34 \mathrm{~mol} \mathrm{ATP} / \mathrm{mol}$ glucose.

Glycerol release was used to assess lipolysis and to evaluate the clearance by the heart of another metabolite besides lactate. Inasmuch as supplementary fatty acids were not included in the perfusate, endogenous myocardial triglycerides became the primary source of lipids available for metabolism. Triglycerides can be hydrolized to glycerol and FFA, and heart tissue is deficient in glycerol kinase (16). Thus, glycerol release can be used as an indirect marker for hydrolysis of triglycerides. Glycerol concentrations were measured on arterial and venous perfusate samples, using a fluorometric assay (17). Rates of glycerol release $\left(\mathrm{nmol} / \mathrm{min} / \mathrm{g}_{\text {wel }}\right)$ were determined from the arteriovenous glycerol concentration difference and coronary flow.

\section{EXPERIMENTAL DESIGN}

Normal oxygen delivery (control group). These experiments were performed to demonstrate that these hearts $(6-12$ g) exhibited prolonged stability under conditions of normal (i.e. adequate) oxygen delivery. Hearts from 11 pigs were excised as previously described. After initiation of retrograde aortic perfusion, the hearts were allowed to stabilize for $\approx 20$ min with a coronary perfusion pressure of $60 \mathrm{~mm} \mathrm{Hg}$, which is the in vivo aortic diastolic pressure measured in piglets (18). The left ventricular EDP was set at $\approx 5 \mathrm{~mm} \mathrm{Hg}$, a normal EDP for a neonate. Typically, the volume of fluid in the balloon, or preload, was $\approx 0.07 \mathrm{~mL} / \mathrm{g}_{\text {wet }}$. Each heart underwent control perfusion for an additional $100 \mathrm{~min}$, which was the average time for the low-flow ischemia protocol. Left ventricular PSP, $+\mathrm{dP} / \mathrm{dt}_{\max }$ and $\mathrm{EDP}$, coronary flow, lactate release, and $\mathrm{MVo}_{2}$ were measured at 10-min intervals. Seven of the 11 hearts were freeze-clamped at the end of this perfusion period for the measurement of myocardial glycogen contents.

Four additional hearts underwent control perfusion for only $20 \mathrm{~min}$ after the initial stabilization period. This perfusion period corresponded to the time of perfusion before inducing ischemia, in the low-flow ischemia protocol. These hearts were freeze-clamped at the end of this period for the measurement of baseline (preischemic) myocardial glycogen contents.

Low-flow ischemia (group I). These experiments were performed to determine mechanical responses, measure lactate release, estimate glycolysis from exogenously supplied glucose, and assess myocardial glycogen contents. Hearts from six pigs were excised as described above. After initiation of retrograde aortic perfusion, the coronary perfusion pressure was fixed at $60 \mathrm{~mm} \mathrm{Hg}$, and the left ventricular EDP at $\approx 5 \mathrm{~mm} \mathrm{Hg}$. Because the volume of fluid in the balloon was held fixed, subsequent changes in EDP reflected alterations in left ventricular diastolic compliance. Hearts were then allowed to stabilize for $\approx 20 \mathrm{~min}$, during which time $\left[{ }^{3} \mathrm{H}\right]$ glucose was added to the perfusate. During this period of time, ${ }^{3} \mathrm{H}_{2} \mathrm{O}$ production reached a steady state, indicating that the isotopically labeled glucose had equilibrated with the endogenous myocardial glucose pool.

After stabilization, each heart underwent three consecutive perfusion periods: 1 ) baseline, 2) normothermic $\left(37^{\circ} \mathrm{C}\right)$ lowflow ischemia, and 3) reperfusion. During baseline, which lasted $20 \mathrm{~min}$, hearts were perfused at a constant coronary perfusion pressure of $60 \mathrm{~mm} \mathrm{Hg}$, and with an EDP of $\approx 5$ $\mathrm{mm} \mathrm{Hg}$. During low-flow ischemia, the coronary flow was abruptly reduced to $10 \%$ of the baseline value, using the constant flow system described previously (11). A fixed coronary flow was used to produce low-flow ischemia, so that global oxygen delivery would remain constant even as myocardial contracture developed. The onset of contracture was defined by a progressive rise in left ventricular EDP. Ischemia was continued until the EDP increased $\approx 2$-fold above the baseline value, to ensure that contracture was sustained.

Hearts were reperfused by abruptly restoring coronary perfusion pressure to the baseline value of $60 \mathrm{~mm} \mathrm{Hg}$ and allowing coronary flow to run freely. Because perfusion pressure was again held constant, coronary flow and thus clearance of metabolites was determined by autoregulation. Reperfusion was continued until the PSP and $+\mathrm{dP} / \mathrm{dt}_{\max }$ stabilized $(\approx 20$ min). Reperfusion was included in this protocol primarily to demonstrate that these piglet hearts recovered function after the severe ischemic challenge.

The following measurements were taken at 5-min intervals: left ventricular PSP, $+\mathrm{dP} / \mathrm{dt}_{\max }$ and EDP, coronary flow, lactate and glycerol release, and ${ }^{3} \mathrm{H}_{2} \mathrm{O}$ production from exogenously supplied $\left[{ }^{3} \mathrm{H}\right]$ glucose. The bolus of lactate released upon reperfusion was determined by collecting four timed samples of coronary venous effluent during the first $\approx 90 \mathrm{~s}$ of reperfusion and analyzing these samples for lactate content. The bolus of glycerol release was determined in a similar fashion. Six additional hearts were subjected to the same low-flow ischemia protocol but freeze-clamped at the conclusion of ischemia, to measure glycogen contents.

Low-flow ischemia (group II). These experiments were conducted to assess aerobic metabolism by measuring oxidation of exogenously supplied glucose and $\mathrm{MVo}_{2}$. Correlations were sought between glucose oxidation and mechanical activity and $\mathrm{MVo}_{2}$. For these studies, six hearts were subjected to the low-flow ischemia protocol. However, during this stabilization period, $\left[{ }^{14} \mathrm{C}\right]$ glucose (instead of $\left[{ }^{3} \mathrm{H}\right]$ glucose) was added 
to the perfusate. Here again, we found that $\approx 20 \mathrm{~min}$ of heart perfusion was sufficient for the exogenously labeled glucose to equilibrate with the endogenous myocardial glucose pool, as reflected by a steady state of ${ }^{14} \mathrm{CO}_{2}$ production. To compare pre- and postischemic metabolic responses, rates of glucose oxidation and $\mathrm{MVO}_{2}$ were normalized to mechanical activity by dividing these metabolic rates by [(PSP-EDP) $\times$ HR].

Low-flow ischemia (group III). Glycerol release was studied in the group I hearts and in four additional hearts that were subjected to the low-flow ischemia protocol.

Data and statistical analysis. Data values are expressed as means \pm SEM. Data obtained during ischemia and reperfusion were analyzed and compared with baseline, using a one-way analysis of variance randomized block design for repeated measures, followed by Dunnett's and/or Newman-Keuls comparison procedure. Differences were considered significant with values of $p<0.05$.

\section{RESULTS}

\section{Normal Oxygen Delivery (Control Group)}

The parameters measured at 20 and $100 \mathrm{~min}$ of perfusion for the control group are shown in Table 1. The myocardial glycogen contents with control perfusion are similar to those reported by Werner et al. (18) for neonatal pig hearts undergoing Langendorff perfusion with a crystalloid solution containing glucose as the sole substrate. These results demonstrate that hearts excised and perfused, as described above, exhibited mechanical and metabolic stability under conditions of normal oxygen availability.

\section{Low-Flow Ischemia (Group I)}

Coronary flow and mechanical function. Figure 1 shows the coronary flow and EDP for the three perfusion periods. During baseline, coronary flow averaged $8.7 \pm 0.7 \mathrm{~mL} / \mathrm{min} /$

Table 1. Parameters measured in 11 hearts at 20 and 100 min of control perfusion

\begin{tabular}{|c|c|c|}
\hline Time (min) & 20 & 100 \\
\hline PSP $(\mathrm{mm} \mathrm{Hg})$ & $111.7 \pm 4.5$ & $106.1 \pm 3.7$ \\
\hline $\mathrm{EDP}(\mathrm{mm} \mathrm{Hg})$ & $4.2 \pm 0.4$ & $5.1 \pm 0.7$ \\
\hline$(+) \mathrm{dP} / \mathrm{dt}_{\max }(\mathrm{mm} \mathrm{Hg} / \mathrm{s})$ & $1234.0 \pm 52.3$ & $1164.0 \pm 42.2$ \\
\hline $\begin{array}{l}\text { Coronary flow } \\
\qquad\left(\mathrm{mL} / \mathrm{min} / \mathrm{g}_{\mathrm{wct}}\right)^{*}\end{array}$ & $7.9 \pm 0.4$ & $8.3 \pm 0.6$ \\
\hline $\begin{array}{l}\text { Lactate release } \\
\qquad\left(\mu \mathrm{mol} / \mathrm{min} / \mathrm{g}_{\mathrm{wet}}\right)\end{array}$ & $0.62 \pm 0.07$ & $0.64 \pm 0.09$ \\
\hline $\mathrm{MVO}_{2}\left(\mu \mathrm{mol} / \mathrm{min} / \mathrm{g}_{\text {wet }}\right)$ & $3.22 \pm 0.15$ & $3.06 \pm 0.17$ \\
\hline $\begin{array}{l}\text { Glycogen }(\mu \mathrm{mol} \text { glucose } \\
\left.\text { equivalent } / \mathrm{g}_{\mathrm{dry}}\right) \dagger\end{array}$ & $234.8 \pm 12.0 \ddagger$ & $224.6 \pm 23.3 \pi$ \\
\hline
\end{tabular}

Values are expressed as means $\pm \mathrm{SEM}$.

* Coronary flow, $\mathrm{MVO}_{2}$, and lactate are expressed per gram wet ( $g_{\text {wet }}$ ) heart weight. Since hearts were freeze-clamped, total wet heart weights were estimated using the regression formula

$$
\text { Heart weight }(\mathrm{g})=[0.0065 \times \text { body weight }(\mathrm{g})]-0.298 \text {. }
$$

$\dagger$ Glycogen $=$ myocardial glycogen content.

$\ddagger$ Measured in four additional hearts freeze clamped after 20 min of perfusion.

I Measured in 7 of the 11 hearts freeze clamped after 100 min of perfusion.

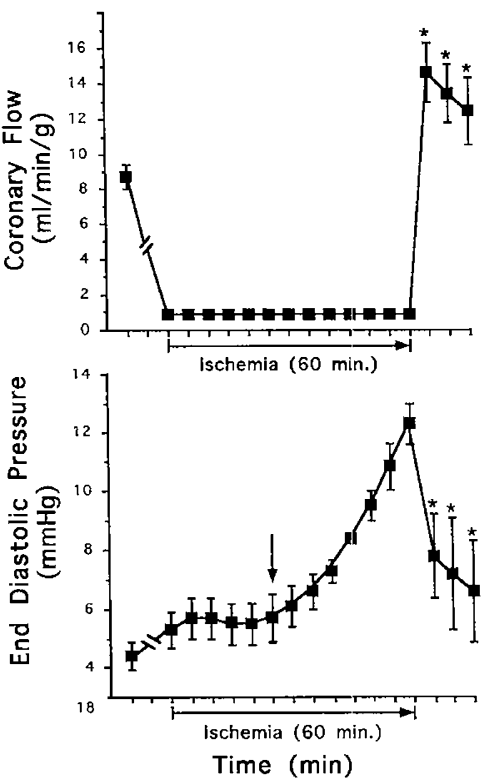

Figure 1. Values of coronary flow, in $\mathrm{mL} / \mathrm{min} / \mathrm{g}_{\text {wet }}$ (top graph), and left ventricular end diastolic pressure, in $\mathrm{mm} \mathrm{Hg}$ (bottom graph), during the three perfusion periods, for the six hearts in group I. The first point represents the average value of the measured parameter during the baseline period. The next 13 points, designated by the horizonal arrow (ischemia), represent the values, at 5 -min intervals, during the last $60 \mathrm{~min}$ of low-flow ischemia. The last three points represent the values during $15 \mathrm{~min}$ of reperfusion. Values are expressed as means \pm SEM. In the bottom graph, the vertical arrow designates the onset of myocardial contracture, as assessed by the rise in end diastolic pressure (see text). Myocardial contracture occurred after $4.1 .7 \pm 4.4 \mathrm{~min}$ of low-flow ischemia. Asterisks indicate the reperfusion values that are statistically different from baseline $(p<0.05)$.

$\mathrm{g}_{\mathrm{wet}}$. During ischemia, coronary flow was held constant at 0.87 $\pm 0.06 \mathrm{~mL} / \mathrm{min} / \mathrm{g}_{\text {wet }}$. Upon reperfusion, coronary flow increased $\approx 70 \%$ above baseline and then decreased toward baseline. During baseline, EDP averaged $4.4 \pm 0.5 \mathrm{~mm} \mathrm{Hg}$. The volume of fluid in the balloon was $0.069 \pm 0.002 \mathrm{~mL} / \mathrm{g}_{\text {wet }}$. With the induction of low-flow ischemia, the EDP decreased slightly below baseline, reflecting the effect of the reduced coronary flow on left ventricular diastolic compliance (19) and then increased, but remained stable. After a period of stability, the EDP for each heart exhibited a progressive rise, indicating the onset of contracture. The time at which this rise occurred, defined the time for the onset of contracure for each heart. At the conclusion of ischemia, the EDP was $12.3 \pm 0.7 \mathrm{~mm} \mathrm{Hg}$. The duration of ischemia for the onset of contracture was 41.7 $\pm 4.4 \mathrm{~min}$, and the total period of ischemia was $78.2 \pm 4.6$ min. During reperfusion, the EDP decreased toward baseline. Unless stated otherwise, the data have been combined so that only values of parameters corresponding to the last $60 \mathrm{~min}$ of low-flow ischemia for each heart are shown.

Figure 2 shows the PSP and $+\mathrm{dP} / \mathrm{dt}_{\max }$. During baseline, PSP averaged $101.1 \pm 5.0 \mathrm{~mm} \mathrm{Hg}$. With the induction of low-flow ischemia, PSP abruptly decreased to $\approx 20 \mathrm{~mm} \mathrm{Hg}$, and remained stable. Toward the end of ischemia, PSP tended to increase slightly, reflecting the rise in EDP. With reperfusion, PSP recovered to $\approx 80 \%$ of baseline. During baseline, $+\mathrm{dP} / \mathrm{dt}_{\max }$ averaged $1103.0 \pm 80.6 \mathrm{~mm} \mathrm{Hg} / \mathrm{s}$. The pattern 

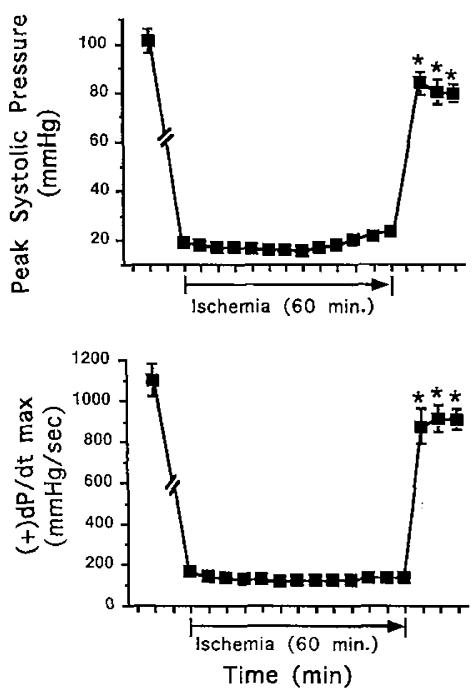

Figure 2. Values of left ventricular peak systolic pressure, in $\mathrm{mm} \mathrm{Hg}$ (top graph), and $(+) \mathrm{dP}_{\mathrm{dt}}$ max , in $\mathrm{mm} \mathrm{Hg} / \mathrm{s}$ (bottom graph), during the three perfusion periods, for the six hearts in group I. The points shown represent the same time periods as in Figure 1. Values are expressed as means \pm SEM. Asterisks indicate the reperfusion values that are statistically different from baseline ( $p$ $<0.05)$.

observed for $+\mathrm{dP} / \mathrm{dt}_{\max }$ was similar to that of PSP, except that $+\mathrm{dP} / \mathrm{dt}_{\max }$ did not rise at the end of ischemia.

Lactate release. Figure 3 (top graph) shows rates of lactate release. During baseline, lactate release averaged $0.71 \pm 0.11$ $\mu \mathrm{mol} / \mathrm{min} / \mathrm{g}_{\text {wet }}$. With the induction of low-flow ischemia, lactate release increased initially to $2.42 \pm 0.09$ and then stabilized at $\approx 2.3 \mu \mathrm{mol} / \mathrm{min} / \mathrm{g}_{\text {wet }}$. After a period of stability, lactate release for each heart began to decline. At the conclusion of ischemia, lactate release was $1.37 \pm 0.11 \mu \mathrm{mol} / \mathrm{min} / \mathrm{g}_{\text {wet }}$ Upon reperfusion, a large bolus of lactate was detected, which represented lactate formed during the previous period of ischemia. Lactate release then returned to baseline within $5 \mathrm{~min}$ of reperfusion. The total lactate produced as a consequence of ischemia (calculated by integrating the area under the lactate
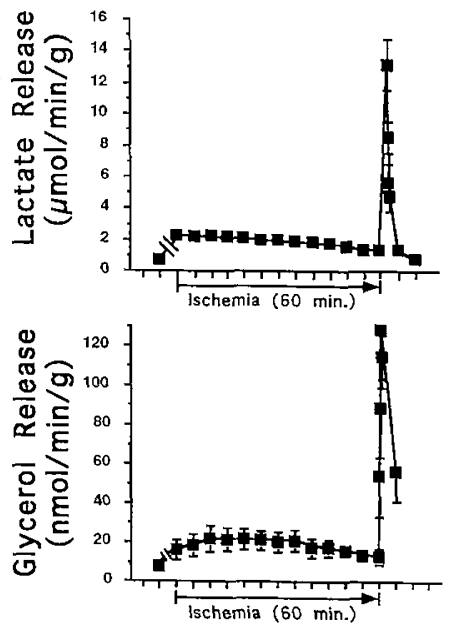

Time (min)

Figure 3. Rates of lactate release, in $\mu \mathrm{mol} / \mathrm{min} / \mathrm{g}_{\text {wet }}$ (top graph), for the six hearts in group 1 . Rates of glycerol release, in $\mathrm{nmol} / \mathrm{min} / \mathrm{g}_{\mathrm{wet}}$ (bottom graph), for the four hearts in group III. Values are expressed as means \pm SEM. release curve for ischemia and the bolus associated with reperfusion) was $154.2 \pm 4.6 \mu \mathrm{mol} / \mathrm{g}_{\text {wet }}$.

Correlation Between EDP and Lactate Release. Figure 4 shows simultaneous values of the left ventricular EDP and lactate release during the last $60 \mathrm{~min}$ of ischemia. The rise in EDP, indicating the onset of contracture (vertical arrow) and the decline in lactate release, began at approximately the same time. Thus, contracture in the neonatal pig heart was associated with a decline in lactate release.

Glycolysis. Figure 5 (top graph) shows rates of glycolysis from exogenously supplied glucose. During baseline, glycolysis averaged $970.5 \pm 65.3 \mathrm{nmol} / \mathrm{min} / \mathrm{g}_{\text {wet }}$. With the induction of low-flow ischemia, glycolysis abruptly decreased to $\approx 400$ $\mathrm{nmol} / \mathrm{min} / \mathrm{g}_{\mathrm{wet}}$ and remained stable. Glycolysis in our piglet hearts returned to baseline values within $5 \mathrm{~min}$ of reperfusion. We observed no significant decline in glycolysis in any heart during the entire period of ischemia, which ranged from 68-98 min, despite the development of contracture.

In the six hearts freeze-clamped at the conclusion of ischemia, the myocardial glycogen content averaged $181.5 \pm 30.3$ $\mu \mathrm{mol}$ of glucose equivalent $/ \mathrm{g}_{\text {dry }}$. This value was not statistically different from the baseline (or preischemic) myocardial glycogen content $(234.8 \pm 12.0 \mu \mathrm{mol}$ of glucose equivalent/ $\left.\mathrm{g}_{\text {dry }}\right)$. The variability in the glycogen contents at the conclusion of ischemia precluded an accurate assessment of glycogenolysis. Nevertheless, no net glycogen turnover was detected as a consequence of ischemia.

\section{Low-Flow Ischemia (Group II)}

Mechanical function. These hearts exhibited almost identical levels of mechanical performance, times for the onset of contracture $(42.6 \pm 3.3 \mathrm{~min})$, and total period of ischemia $(76.3 \pm 7.5 \mathrm{~min})$ to the hearts in group I.

Glucose oxidation. Figure 5 (bottom graph) shows rates of glucose oxidation from exogenously supplied glucose. During baseline, glucose oxidation averaged $165.4 \pm 15.9 \mathrm{nmol} / \mathrm{min} /$ $\mathrm{g}_{\mathrm{wct}}$, which accounted for $\approx 48 \%$ of the oxygen consumed and correlated closely with both mechanical activity $(r=0.957)$, and $\mathrm{MVO}_{2}(r=0.991)$. With the induction of low-flow ischemia, glucose oxidation abruptly decreased to $\approx 17 \mathrm{nmol} / \mathrm{min} /$ $\mathrm{g}_{\mathrm{we}}$, reflecting the corresponding decrease in developed pressure. Glucose oxidation initially remained stable and then

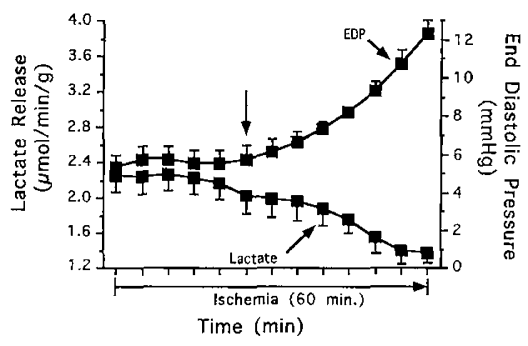

Figure 4. Simultaneous values of lactate release (bottom curve) and left ventricular end diastolic pressure (top curve), at 5-min intervals, during the last $60 \mathrm{~min}$ of ischemia. The scale for lactate release is on the left-sided ordinate, and the scale for end diastolic pressure is on the right. The vertical arrow designates the onset of myocardial contracture. Values are expressed as means \pm SEM 
began to decline, at approximately the time at which contracture developed $(p<0.01)$. Glucose oxidation accounted for $\approx 39 \%$ of the oxygen consumed early in ischemia, but declined to $\approx 28 \%$ by the end of ischemia. During reperfusion, glucose oxidation returned to baseline values within $10 \mathrm{~min}$; however, glucose oxidation now correlated poorly with both mechanical activity $(r=0.574)$, and $\mathrm{MVO}_{2}(r=0.327)$.

$M V_{0} 2$, glucose oxidation and glycolysis normalized to mechanical activity. Myocardial oxygen consumption and glucose oxidation normalized to mechanical activity are shown in Figure 6, A and B, for the three perfusion periods. For comparison, the glycolytic rates for the group I hearts were also indexed to mechanical activity (Fig. 6C). A greater amount of oxygen was consumed per $\mathrm{mm} \mathrm{Hg}$ of pressure development during ischemia than during baseline $(p<0.05)$. Furthermore, for all the hearts studied, the instantaneous value of $\mathrm{MVO}_{2}$ indexed to mechanical activity increased $\approx 40 \%$ from the beginning of ischemia to contracture. Myocardial oxygen consumption normalized to mechanical activity also remained elevated during reperfusion (although not statistically different from baseline). Glycolysis relative to mechanical activity markedly increased during ischemia compared with baseline $(p<0.05)$, whereas glucose oxidation became enhanced upon reperfusion $(p<0.05)$.

\section{ATP Production Associated with Glucose Utilization}

Average rates of ATP production associated with glycolysis (group I) and glucose oxidation (group II) were calculated. These results are presented in Table 2. During baseline, glycolysis accounted for $26 \%$ and glucose oxidation $74 \%$ of total calculated ATP from exogenous glucose utilization. In contrast, during ischemia, these percentages changed to 58 and $42 \%$, respectively. During reperfusion, the percentages returned to baseline values. Our baseline percentages are somewhat different from those ( 14 and $86 \%$, respectively) calculated
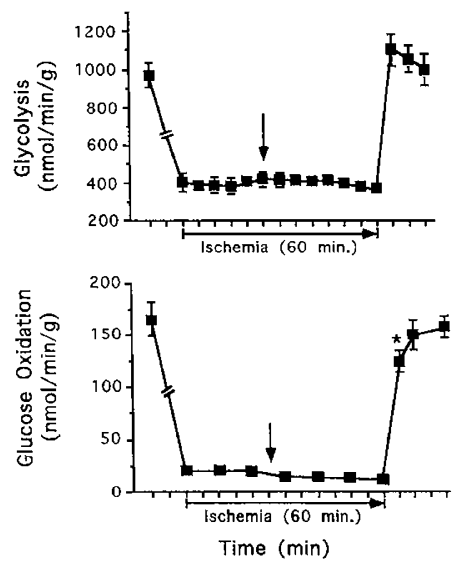

Figure 5. Rates of glycolysis, in $\mathrm{nmol} / \mathrm{min} / \mathrm{g}_{\mathrm{wct}}$ (top graph), during the three perfusion periods, for the six hearts in group I. Rates of glucose oxidation, in $\mathrm{nmol} / \mathrm{min} / \mathrm{g}_{\text {wet }}$ (bottom graph), during the three perfusion periods, for the six hearts in group II. Vertical arrow designates the onset of myocardial contracture for each group of hearts. Values are expressed as means \pm SEM. Asterisks indicate the reperfusion values that are statistically different from baseline ( $p$ $<0.05$ ).
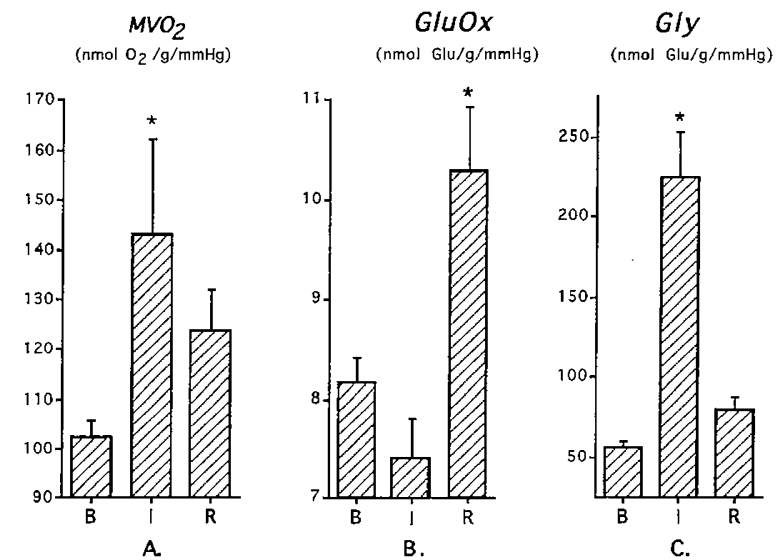

Figure 6. Metabolic rates to mechanical activity, i.e.

$$
\frac{\text { Metabolic rate }\left(\mathrm{nmol} / \mathrm{min} / \mathrm{g}_{\mathrm{wct}}\right) \times 10^{3}}{(\mathrm{PSP}-\mathrm{EDP}) \times \mathrm{HR}(\mathrm{mm} \mathrm{Hg} / \mathrm{min})}
$$

$A$, Myocardial oxygen consumption to mechanical activity $\left(\mathrm{MVO}_{2}\right) ; \mathrm{B}$, glucose oxidation to mechanical activity $(G l u O x)$; and $C$, glycolysis to mechanical activity $(G l y)$, are shown for the three perfusion periods $(B=$ baseline, $I=$ ischemia, and $R=$ reperfusion). Asterisks indicate that, during ischemia, $\mathrm{MVO}_{2}$ and Gly are enhanced relative to baseline $(p<0.05)$; whereas, during reperfusion, GluOx becomes enhanced $(p<0.05)$. The remaining metabolic rates are not statistically different from baseline.

from the results of Neely et al. (20) for isolated rat hearts perfused with a buffer solution, reflecting the higher oxidation rates in mature hearts.

\section{Low-Flow Ischemia (Group III)}

Figure 3 (bottom graph) shows rates of glycerol release for the four additional hearts subjected to the low-flow ischemia protocol. During baseline, glycerol release averaged $7.8 \pm 2.3$ $\mathrm{nmol} / \mathrm{min} / \mathrm{g}_{\text {wet }}$. Within $5 \mathrm{~min}$ of ischemia, glycerol release was stimulated, and it stabilized at $\approx 20 \mathrm{nmol} / \mathrm{min} / \mathrm{g}$ wet. With the onset of contracture, glycerol release began to decline, as was observed for lactate release. At the conclusion of ischemia, glycerol release was $12.7 \pm 4.2 \mathrm{nmol} / \mathrm{min} / \mathrm{g}_{\text {wet }}$, a comparable decline as with lactate (Fig. 3, top graph) Upon reperfusion, a bolus of glycerol was detected, which likely represented glycerol formed during the previous period of ischemia. The hearts in group I exhibited a similar pattern of glycerol release.

\section{DISCUSSION}

In these studies, we investigated mechanical and metabolic responses in neonatal pig hearts subjected to low-flow ischemia. Hearts were perfused with a crystalloid solution so that severe oxygen insufficiency would be created during myocardial underperfusion, and thus contracture would be a feature of these hearts. These hearts exhibited stability with this preparation under conditions of normal oxygen availability. When hearts were subjected to reduced oxygen delivery $(10 \%$ of baseline), however, PSP and $+\mathrm{dP} / \mathrm{dt}_{\text {max }}$ decreased abruptly, but then remained stable. Oxygen extraction increased from a mean value of $49 \%$ during baseline to $81 \%$ with ischemia, and lactate release increased $\approx 3-4$ fold. After $\approx 40$ min of myo- 
Table 2. Calculated average rates of ATP production from exogenously supplied glucose

\begin{tabular}{lccccccc}
\hline \multirow{2}{*}{$\begin{array}{c}\text { Modc of ATP } \\
\text { production }\end{array}$} & \multicolumn{3}{c}{ ATP production $\left(\mathrm{nmol} / \mathrm{min} / \mathrm{g}_{\text {wet }}\right)$} & & \multicolumn{3}{c}{ Percent of total calculated ATP } \\
\cline { 2 - 4 } & Baseline & Ischemia & Reperfusion & & Baseline & Ischemia & Reperfusion \\
\hline Glycolysis & 1941 & 800 & 2095 & 26 & 58 & 29 \\
Glucose oxidation & 5624 & 568 & 5243 & 74 & 42 & 71 \\
Total ATP & 7565 & 1368 & 7338 & 100 & 100 & 100 \\
\hline
\end{tabular}

Thesc rates were calculatcd assuming: $2 \mathrm{~mol}$ of ATP/mol of exogenous glucose (glycolysis) and $34 \mathrm{~mol}$ of ATP/mol of exogenous glucose (glucose oxidation).

cardial underperfusion, hearts developed contracture, as evidenced by a progressive rise in left ventricular EDP.

The mechanisms responsible for reduced contractility and the development of contracture with ischemia are incompletely understood. Reduced oxygen delivery can impair ATP formation, resulting in net ATP hydrolysis. This process leads to depletion of ATP and accumulation of inorganic phosphate (and $\mathrm{H}^{+}$), which are known to depress myofibril function (21). Obviously, these mechanisms are interrelated, because $\mathrm{pH}$ can alter ATP hydrolysis, and, conversely, ATP is required for $\mathrm{pH}$ regulation. Furthermore, recent work by Tani and Neely (22) in mature rat hearts suggests that $\mathrm{Na}^{+}-\mathrm{H}^{+}$and $\mathrm{Na}^{+}-\mathrm{Ca}^{2+}$ exchange may be involved in ischemic myocardial dysfunction. It has been proposed that intracellular $\mathrm{H}^{+}$exchanges with $\mathrm{Na}^{+}$ during ischemia. The corresponding increase in intracellular $\mathrm{Na}^{+}$activates the $\mathrm{Na}^{+}-\mathrm{Ca}^{2+}$ pump, resulting in excessive $\mathrm{Ca}^{2+}$ uptake and altered diastolic chamber compliance. The importance of such ion fluxes in the neonatal heart, however, remains to be elucidated.

Although the neonatal hearts used in this study developed contracture during ischemia, PSP and $+\mathrm{dP} / \mathrm{dt}_{\max }$ returned to $\approx 80 \%$ of baseline values upon reperfusion. These results are consistent with our previous findings (23) and the recent reports by Matherne et al. (24) and Downing and Chen (25) that immature hearts demonstrate tolerance to low-flow ischemia and exhibit good recovery of contractile function upon reperfusion. Functional recovery after an ischemic challenge is believed to reflect an enhanced capacity to maintain ATP stores and $\mathrm{H}^{+}$balance during the previous ischemic episode. Recent work by Matherne et al. (24), using ${ }^{31} \mathrm{P}-\mathrm{NMR}$ spectroscopy, has shown that neonatal rabbit hearts are more resistant to global ischemia than are their adult counterparts and that intracellular ATP and $\mathrm{pH}$ are maintained more effectively in the immature myocardium.

In contrast, other investigators have suggested that the neonatal heart may be particularly susceptible to ischemic injury $(4,26,27)$. It has been postulated that the enhanced capacity of the immature heart for anaerobic glycolysis leads to rapid accumulation of lactate (and $\mathrm{H}^{+}$), which accelerates myocardial injury during oxygen insufficiency (4). However, in these studies, neonatal hearts were subjected to zero coronary flow. In contrast, our model allows for continuous perfusion of the myocardium. A minimal level of coronary flow may be required to provide washout of metabolites and thus prevent a critical buildup of lactate.

An important finding in the present study was that the increase in ventricular diastolic stiffness (contracture) during ischemia in these neonatal hearts occurred in conjunction with a decline in lactate release. This decline in lactate release may reflect a decrease in lactate production. Previous investigations, for example, have demonstrated that glycolytic flux, and thus lactate production, may become inhibited during ischemia by an accumulation of metabolites and $\mathrm{H}^{+}(14,28)$. Recently, Kingsley et al. (29), using ${ }^{31} \mathrm{P}-\mathrm{NMR}$ spectroscopy to measure intracellular $\mathrm{pH}$, demonstrated that contracture in mature rat hearts correlated with a plateau in intracellular $\mathrm{pH}$. They suggested that contracture, at least in the arrested heart, may be associated with a cessation of anaerobic glycolysis. With lowflow ischemia, however, there can be washout of $\mathrm{H}^{+}$; thus, a decline or cessation in $\mathrm{H}^{+}$formation would be expected to be associated with a rise, rather than a plateau, in intracellular $\mathrm{pH}$. Because, in our hearts, the rate of glycolysis from exogenously supplied glucose was stable during ischemia, a decrease in lactate and/or $\mathrm{H}^{+}$production with contracture may be related to: 1) a decrease in glycogen utilization and 2) nonglycolytic pathways for lactate production. In the first case, we found no net turnover of glycogen, based on changes in myocardial glycogen contents. In the second case, however, nonglycolytic pathways have been identified for anaerobic energy production, and are discussed below (30).

The decline in lactate release during contracture may also be related to impaired lactate clearance. Stein et al. (31) have shown that intramyocardial diastolic pressures exceed intracavity diastolic pressures in the left ventricle of the normal dog heart. It is probable that intramyocardial diastolic pressures exceeded intraventricular balloon diastolic pressures in these piglet hearts. Moreover, contracture and edema may have augmented intramyocardial diastolic pressures during the lowflow state. Because coronary extravascular compression is directly related to intramyocardial pressure, we speculate that lactate clearance may have been further impaired by the onset of contracture. The decline in both glycerol and lactate release during contracture is consistent with the notion of impaired clearance. Inasmuch as coronary flow was held constant, however, a compression of the coronary vasculature would be reflected in a redistribution of flow, probably from endocardium toward epicardium.

In the present study, glycolysis was investigated under baseline conditions and during the ischemic challenge. Our baseline rates of glycolysis are similar to those reported by Werner et al. $(18,32)$ for neonatal pig hearts, when wet to dry heart weight ratios are taken into account. With the induction of low-flow ischemia, glycolysis decreased $\approx 50-60 \%$ from baseline, which is comparable to the reduction in glycolysis observed by Neely et al. (20) for isolated mature rat hearts subjected to severe ischemia. Moreover, the onset of myocardial contracture in our piglet hearts was associated with stable rates of glycolysis. Thus, contracture was not caused by a 
decline in exogenous glucose utilization per se. However, ATP stores in the region of the contractile apparatus probably became depleted by $\approx 40 \mathrm{~min}$ of ischemia, and it is conceivable that contracture may have occurred as a consequence of an insufficient rate of glycolysis. Recently, Owen et al. (6) and Eberlie et al. (33) have shown that a minimal rate of ATP production from glycolysis $\left(\approx 2.0 \mu \mathrm{mol} \mathrm{ATP} / \mathrm{min} / \mathrm{g}_{\mathrm{wet}}\right)$ was required to prevent ischemic contracture in mature hearts. In our experiments, we estimate that the rate of ATP production from glycolysis during ischemia was $\approx 0.8 \mu \mathrm{mol} \mathrm{ATP} / \mathrm{min} /$ $\mathrm{g}_{\text {wet }}$. Contracture in these neonatal hearts, therefore, may have been related to an inadequate rate of ongoing, glycolytic ATP production.

The present study also suggests that net lactate production $\left(\approx 154 \mu \mathrm{mol} / \mathrm{g}_{\text {wet }}\right.$ ) may not fully be accounted for by glycolysis from exogenously supplied glucose. The net lactate ascribed to glucose was $\approx 75 \mu \mathrm{mol} / \mathrm{g}_{\text {wet }}$, assuming $2 \mathrm{~mol}$ of lactate per mol of glucose. Thus, only $\approx 50 \%$ of the measured lactate during ischemia was accounted for by glucose utilization. One possibility for this apparent discrepancy may lie in an underestimate of the radioisotopically determined rate of glycolysis during ischemia. For example, unlabeled glucose from glycogenolysis could dilute the pool of labeled glucose being taken up from the perfusate, resulting in a lower measured rate of glycolysis. However, in our experiments, hearts were equilibrated with $\left[{ }^{3} \mathrm{H}\right]$ glucose and insulin for $\approx 50 \mathrm{~min}$ before inducing ischemia. Thus, a sufficient time was allowed for incorporation of labeled glucose into glycogen and for the perfusate glucose radioactivity to equilibrate with that of the endogenous glucose pool $(34,35)$. This issue, however, deserves additional investigation.

Recent studies by Wittnich et al. (3) on globally ischemic neonatal pig hearts also suggest that net lactate production may not be accounted for by glycogenolysis. In these studies, piglet hearts were subjected to no-flow arrest, until the development of contracture, by immersing hearts in a glucose-free buffer solution. Based on their measured changes in myocardial glycogen $\left(\approx 6 \mu \mathrm{mol} / \mathrm{g}_{\mathrm{wet}}\right)$ and lactate $\left(\approx 20 \mu \mathrm{mol} / \mathrm{g}_{\mathrm{wct}}\right)$ contents, one can account for only $\approx 60 \%$ of the lactate produced from glycogenolysis during the arrested state. A possible explanation for a discrepancy between measured and calculated lactate production may lie in the formation of lactate from other sources, such as amino acids and/or Krebs cycle metabolites (36). Amino acids can act as metabolic substrates during oxygen insufficiency, using transamination reactions and the malate-aspartate shuttle to form high energy phosphates (37). Pyruvate formed from these reactions can subsequently be converted to lactate via lactate dehydrogenase. Recent studies by Julia et al. (38) have shown that such nonglycolytic pathways may become important sources of energy in ischemic puppy hearts.

We have also assessed aerobic metabolism in these neonatal hearts, by measuring rates of glucose oxidation and $\mathrm{MVO}_{2}$. Under conditions of normal oxygen delivery, rates of glucose oxidation and $\mathrm{MVO}_{2}$ were closely linked to mechanical activity. During low-flow ischemia, the average rate of glucose oxidation decreased to $10 \%$ of baseline, consistent with the decrease in oxygen delivery. Nevertheless, glucose oxidation still provided an important source of ATP during myocardial underperfusion, accounting for $\approx 42 \%$ of the net ATP derived from glucose. When indexed to mechanical activity, however, glucose oxidation tended to fall, and glycolysis markedly increased, consistent with the concept of a greater reliance on glycolysis during impaired oxygen availability. Surprisingly, $\mathrm{MVO}_{2}$, when referenced to mechanical activity, was found to increase $(\approx 40 \%)$ during ischemia. A relative increase in oxygen consumption during ischemia would not have been anticipated; however, we have found a similar result with more modest degrees of low-flow ischemia (23), and an increase in oxygen consumption (relative to mechanical activity) has also been reported for globally ischemic immature rabbit hearts (24). In view of the tolerance of neonatal hearts to low-flow ischemia, it is conceivable that this relative increase in oxygen consumption during myocardial underperfusion may result from a beneficial process, i.e. an oxygen-consuming process that nevertheless helps maintain ATP stores. Reperfusion was characterized by enhanced glucose oxidation relative to mechanical activity. This finding is consistent with our earlier work which demonstrated an acceleration of fatty acid oxidation in postischemic piglet hearts (23). An additional finding was that glucose oxidation and $\mathrm{MVO}_{2}$ correlated poorly with mechanical activity during reperfusion, indicating a dissociation between contractile function and aerobic metabolism. Such an uncoupling between contractile activity and aerobic metabolism during early reperfusion may reflect an attempt by the heart to replenish ATP stores after the severe ischemic challenge.

Finally, this study implies that myocardial triglycerides undergo hydrolysis during low-flow ischemia. Such a process is of importance, becaue an increase in intracellular FFA could potentially have deleterious effects upon the oxygen limited heart $(39,40)$. The total glycerol produced, and thus triglyceride hydrolyzed, during ischemia (group I) was $\approx 930 \mathrm{nmol} /$ $\mathrm{g}_{\mathrm{wet}}$. The total triglyceride content measured by Werner et al. (41) in newborn pig hearts is $\approx 1000 \mathrm{nmol} / \mathrm{g}_{\text {wet }}$. Thus, a substantial portion of the myocardial triglyceride pool in our piglet hearts may have undergone lipolysis during the low-flow state. The mechanism underlying an enhanced rate of lipolysis during ischemia is incompletely understood, although Schoonderwoerd et al. (16) have provided evidence to suggest that triglyceride breakdown is stimulated by an elevated $\mathrm{NADH} / \mathrm{NAD}^{+}$ratio. Because $\beta$-oxidation is impaired during ischemia, re-esterification of the FFA back to triglycerides becomes the primary means of removing the potentially harmful intracellular lipids. This cycle, however, is an ATPconsuming process $(16,42,43)$. Based on the glycerol release, and assuming that glycerol 3-phosphate comes from glycogenolysis, we estimate that ATP utilization from the breakdown of triglycerides and complete reesterification of the FFA would constitute only $\approx 6 \%$ of the ATP production from glucose.

In summary, we have found that isolated, isovolumically beating neonatal pig hearts develop myocardial contracture when perfused with a crystalloid solution and with a coronary flow reduced to $10 \%$ of baseline. Myocardial contracture was associated with a decline in lactate release, suggesting a de- 
crease in lactate production and/or impaired lactate clearance. Despite the development of contracture, these hearts exhibited stable rates of glycolysis from exogenously supplied glucose. Moreover, glycolysis accounted for only $\approx 50 \%$ of the lactate produced, which may suggest nonglycolytic sources for energy production. Additionally, glycerol release was enhanced during myocardial underperfusion, indicating hydrolysis of triacylglycerols. Although glucose oxidation was impaired during ischemia, glucose oxidation still provided an important source of ATP. Despite the severe ischemic challenge, these neonatal hearts exhibited functional recovery upon reperfusion. Glycolysis and glucose oxidation returned to baseline values although contractile function was depressed, indicating a dissociation between mechanical and metabolic recovery.

\section{REFERENCES}

1. Katz AM, Tada M 1977 The "stone heart" and other challenges to the biochemist. Am J Cardiol 89:1073-1077

2. Grossman W, Barry WH 1980 Diastolic pressure-volume relationship in the human diseased heart. Fed Proc 39:148-155

3. Wittnich C, Peniston C, Ianuzzo D, Abel JG, Salerno TA 1987 Relative vulnerability of neonatal and adult hearts to ischemic injury. Circulation 76(suppl V):156-160

4. Chiu RC-J, Bindon W 1987 Why are newborn hearts vunerable to global ischemia? Circulation 76(suppl V):146-149

5. Hearse DJ, Garlick PB, Hunphrey SM 1977 Ischemic contracture of the myocardium: Mechanisms and prevention. Am J Cardiol 39:986-993

6. Owen P, Dennis S, Opie LH 1990 Glucose flux regulates onset of ischemic contracture in globally underperfused rat hearts. Circ Res 66:344-354

7. Lopaschuk GD, Wambolt RB, Barr RL 1993 An imbalance between glycolysis and glucose oxidation is a possible explanation for the detrimental effects of high levels of fatty acids during aerobic reperfusion of ischemic hearts. J Pharmacol Exp Ther 264:135-144

8. Clark BJ III, Woodford EJ, Malek EJ, Norwood CR, Pigott JD, Norwood WI 1991 Effects of potassium cardioplegia on high-energy phosphate kinetics during circulatory arrest with deep hypothermia in the newborn piglet heart. $J$ Thorac Cardiovasc Surg 101:342-349

9. Ascuitto RJ, Ross-Ascuitto NT, Chen V, Downing SE 1989 Ventricular function and fatty acid metabolism in the neonatal pig heart. Am J Physiol 256:H9-H15

10. Ross-Ascuitto NT, Ascuitto RJ, Ramage D, McDonough KH 1.991 The effects of milrinone in the neonatal pig heart. Cardiovasc Drugs Ther 5:1011-1019

11. Ascuitto RJ, Ross-Ascuitto NT, Ramage D, McDonough KH, Kadowitz PJ 1992 Acetylcholine-induced coronary vasconstriction and negative inotropy in the neonatal pig heart. Pediatr Res 32:236-242

12. Lowry OH, Passoneau JV 1972 A Flexible System of Enzymatic Analysis. Academic Press, New York, pp 199--200

13. Neely JR, Denton RM, England PJ, Randle PJ, 1972 The effects of increased heart work on the tricarboxylate cycle and its interactions with glycolysis in the perfused rat heart. Biochem J 128:147-159

14. Rovetto MJ, Lamberton WF, Neely JR 1975 Mechanisms of glycolytic inhibition in ischemic rat hearts. Circ Res 37:742-75

15. Keppler D, Decker K 1984 In: Bergmeyer, HU (ed) Methods of Enzymatic Analysis, 3rd Ed, Vol VI. Academic Press, New York, pp 11-19

16. Schoonderwoerd K, Broekhoven-Schokker S, Hulsmann C, Stam H 1989 Enhanced lipolysis of myocardial triglycerides during low-flow ischemia and anoxia in the isolated rat heart. Basic Res Cardiol 84:165-173

17. Fain JN, Czech MP, Saperstein R 1973 Growth hormone in vitro, effects on lipolysis. In: Methods in Investigative and Diagnostic Endocrinology. North Holland, Amsterdam, pp 267-273
18. Werner JC, Whitman V, Fripp RR, Schuler HG, Morgan HE 1981 Carbohydrate metabolism in isolated, working newborn pig heart. Am J Physiol 241:E364-E371

19. Vogel WM, Apstein CS, Briggs LL, Gaasch WH, Ahn J 1982 Acute alterations in left ventricular diastolic chamber stiffness. Circ Res 51:465-478

20. Neely JR, Liedtke AJ, Whitmer JT, Rovetto MJ 1975 Relationship between coronary flow and adenosine triphosphate production from glycolysis and oxidative metabolism. Recent Adv Stud Card Struct Metab. 8:301-321

21. Solaro RJ, Lee JA, Kentish JC, Allen DG 1988 Effect of acidosis on ventricular muscle from adult and neonatal rats. Circ Res 63:779-787

22. Tani M, Neely JR 1989 Role of intracellular $\mathrm{Na}^{+}$in $\mathrm{Ca}^{2+}$ ovcrload and depressed recovery of ventricular function of reperfused ischemic rat hearts Circ Res 65:10451056

23. Ascuitto RJ, RossuAscuitto NT, Ramage D, McDonough KH 1990 Mechanical function and fatty acid oxidation in the neonatal pig heart with ischemia and reperfusion. J Dev Physiol 14:249-257

24. Matherne GP, Headrick JP, Berr S, Berne RM 1993 Metabolic and functional responses of immature and mature rabbit hearts to hypoperfusion, ischemia, and reperfusion. Am J Physiol 264:H2141--H2153

25. Downing SE, Chen V 1990 Myocardial hibernation in the ischemic neonatal heart. Circ Res 66:763-772

26. Wittnich C, Chui RC-J 1984 Is the neonatal myocardium more or less vulnerable to ischemic injury? Circulation 72 (suppl III):361

27. Parrish MD, Payne A, Fixler DE 1987 Global myocardial ischemia in the newborn, juvenile, and adult isolated isovolumic rabbit heart: Age related differences in systolic function, diastolic stiffness, coronary resistance, myocardial oxygen consumption, and extracellular pH. Circ Res 61:609-615

28. Neely JR, Grotyohann LW 1984 Role of glycolytic products in damage to ischemic myocardium. Dissociation of adenosine triphosphate levels and recovery of function of reperfused ischemic hearts. Circ Res 55:816-824

29. Kingsley PB, Sako EY, Yang MQ, Zimmer SD, Ugurbil K, Foker JE, From AHL 1991 Ischemic contracture begins when anaerobic glycolysis stops: A ${ }^{31}$ P-NMR study of isolated rat hearts. Am J Physiol 261:H469-H478

30. Hochachka PW, Owen TG, Allen JF, Whittow GC 1975 Multiple end products of anaerobiosis in diving vertebrates. Comp Biochem Physiol 50B:17--22

31. Stein PD, Marzilli M, Sabbah HN, Lee T 1980 Systolic and diastolic pressure gradients within the left ventricular wall. Am J Physiol 238:H625-H630

32. Werner JC, Whitman V, Vary TC, Fripp RR, Musselman J, Schuler HG 1983 Fatty acid and glucose utilization in isolated, working newborn pig hearts. Am J Physiol 244:E19-E23

33. Eberlie FR, Weinberg EO, Grice WN, Horowitz GL, Apstein CS 1991 Protective effect of increased glycolytic substrate against systolic and diastolic dysfunction and increased coronary resistance from prolonged global underperfusion and reperfusion in isolated rabbit hearts perfused with erythrocytes suspensions. Circ Res 68:466-481

34. Chen V, McDonough KH, Spitzer JJ 1985 Effects of insulin on glucose metabolism in isolated heart myocytes from adult rats. Biochim Biophys Acta 846:398-404

35. Das I 1973 Effect of heart work and insulin on glycogen metabolism in the perfused rat heart. Am J Physiol 224:7-12

36. Owen TG, Hochachka PW 1974 Purification and properties of dolphin muscle aspartate and alanine transaminases and their possible role in the energy metabolism of diving mammals. Biochem J 143:541-553

37. Stryer L, 1975 Biochemistry. WH Feeman, San Francisco, pp 293, 432-455

38. Julia PL, Kofsky ER, Buckberg GD, Young HH, Bugyi HI 1990 Studies of myocardial protection in the immature heart. J Thorac Cardiovasc Surg 100:879-887

39. Lamers JMJ, Hulsmann WC 1977 Inhibition of $\left(\mathrm{Na}^{+}+\mathrm{K}^{+}\right)$-stimulated ATPase of heart by fatty acids. J Mol Cell Cardiol 9:343-346

40. Katz AM, Nash-Adler P, Miceli J, Messineo F, Lewis CF 1979 Inhibition of Ca-efflux from the sarcoplasmatic reticulum by free fatty acids. Circulation 59:11-12

41. Werner JC, Sicard RE, Schuler HG 1989 Palmitate oxidation by isolated working fetal and newborn pig hearts. Am J Physiol 256:E315-E321

42. Riemersma RA 1987 Raised plasma non-esterified fatty acids (NEFA) during ischemia: Implications for arrhythmias. Basic Res Cardiol 82(suppl I)177-186

43. Trach V, Buschmans-Denkel E, Schaper W 1986 Relationship between lipolysis and glycolysis during ischemia in the isolated rat heart. Basic Res Cardiol 81:454-464 